Western University

Scholarship@Western

Aboriginal Policy Research Consortium International (APRCi)

$11-2012$

\title{
How to make climate change research relevant for Indigenous communities in Torres Strait, Australia
}

Claire O'Neill

Donna Green

Willie Lui

Follow this and additional works at: https://ir.lib.uwo.ca/aprci

Part of the Place and Environment Commons

Citation of this paper:

O'Neill, Claire; Green, Donna; and Lui, Willie, "How to make climate change research relevant for Indigenous communities in Torres Strait, Australia" (2012). Aboriginal Policy Research Consortium International (APRCi). 382.

https://ir.lib.uwo.ca/aprci/382 
This article was downloaded by: [University of Western Ontario]

On: 18 November 2012, At: 06:54

Publisher: Routledge

Informa Ltd Registered in England and Wales Registered Number: 1072954 Registered

office: Mortimer House, 37-41 Mortimer Street, London W1T 3J H, UK

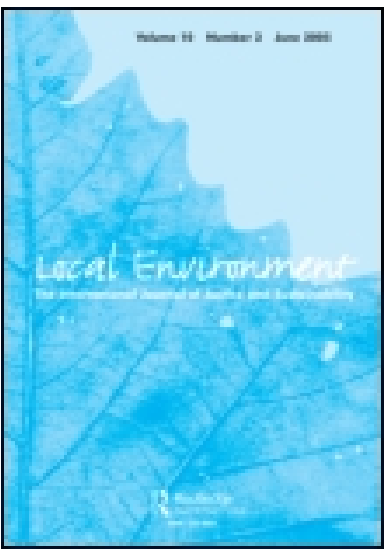

\section{Local Environment: The International J ournal of J ustice and Sustainability}

Publication details, including instructions for authors and subscription information:

http:// www.tandfonline.com/loi/ cloe20

\section{How to make climate change research relevant for Indigenous communities in Torres Strait, Australia}

Claire O'Neill ${ }^{a}$, Donna Green ${ }^{a} \&$ Willie Lui ${ }^{b}$

${ }^{a}$ Climate Change Research Centre, The University of New South Wales, Sydney, 2052, Australia

${ }^{\mathrm{b}}$ Torres Strait Island Regional Council, Warraber, Warraber Island, Australia

Version of record first published: 28 Aug 2012.

To cite this article: Claire O'Neill, Donna Green \& Willie Lui (2012): How to make climate change research relevant for Indigenous communities in Torres Strait, Australia, Local Environment: The International J ournal of J ustice and Sustainability, 17:10, 1104-1120

To link to this article: http:// dx.doi.org/10.1080/13549839.2012.716405

\section{PLEASE SCROLL DOWN FOR ARTICLE}

Full terms and conditions of use: http://www.tandfonline.com/page/terms-andconditions

This article may be used for research, teaching, and private study purposes. Any substantial or systematic reproduction, redistribution, reselling, loan, sub-licensing, systematic supply, or distribution in any form to anyone is expressly forbidden.

The publisher does not give any warranty express or implied or make any representation that the contents will be complete or accurate or up to date. The accuracy of any instructions, formulae, and drug doses should be independently verified with primary sources. The publisher shall not be liable for any loss, actions, claims, proceedings, demand, or costs or damages whatsoever or howsoever caused arising directly or indirectly in connection with or arising out of the use of this material. 


\title{
How to make climate change research relevant for Indigenous communities in Torres Strait, Australia
}

\author{
Claire O’Neill $^{\mathrm{a} *}$, Donna Green ${ }^{\mathrm{a}}$ and Willie Lui ${ }^{\mathrm{b}}$ \\ ${ }^{a}$ Climate Change Research Centre, The University of New South Wales, Sydney 2052, Australia; \\ ${ }^{b}$ Torres Strait Island Regional Council, Warraber, Warraber Island, Australia
}

\begin{abstract}
Several Torres Strait communities have significant infrastructure and sacred sites located only a few metres above sea level. As a consequence, these areas are vulnerable to erosion due to the projected increase in storm surge intensity caused by climate change. Common sense suggests that Islanders would welcome new scientific research about how climate change might affect them, in order to understand the significance of these impacts and the timeframes involved. However, one leader has taken a seemingly counterintuitive stance, and has refused to let new climate research occur. We explore why this position was taken, and the implications of this decision for ongoing scientific research. In order to carry out this analysis, we provide a contextual background by assessing Islanders' recent experience with scientific researchers, and the response of policy-makers to it. We find that despite a clearly documented problem with "top-down" decision-making, this process remains. In this instance, we find that there is a systemic lack of collaboration with Islanders to allow them to prioritise their concerns, and a lack of adequate resources to allow them to build their resilience to climate impacts. We conclude that only through a genuine collaborative approach to climate adaptation can activities be properly developed, prioritised and undertaken.
\end{abstract}

Keywords: Indigenous; climate impacts; adaptation; Indigenous research methodology; Torres Strait

\section{Introduction}

Stretching from the northern tip of Cape York in far north Queensland to the coast of Papua New Guinea's Western Province, Torres Strait encompasses an area of over 40,000 $\mathrm{km}^{2}$. Over $90 \%$ of the Torres Strait region is ocean, which illustrates the critical role that "sea country" plays in Islander culture. Sea country provides the resource for a subsistencebased livelihood, and it is also an integral part of Islander identity, and both their spiritual and physical well-being (Figure 1).

While there are over 150 islands in Torres Strait, there are only 17 established communities on them. Geographically, there are four distinct clusters. The eastern group is made up of high, volcanic islands. The western group are high rocky islands, the remains of the land bridge that once connected Australia to Papua New Guinea. The top western group comprises two low-lying islands and one small high volcanic island, and the central group are predominantly coral cays.

*Corresponding author. Email: claire.oneill@unsw.edu.au 


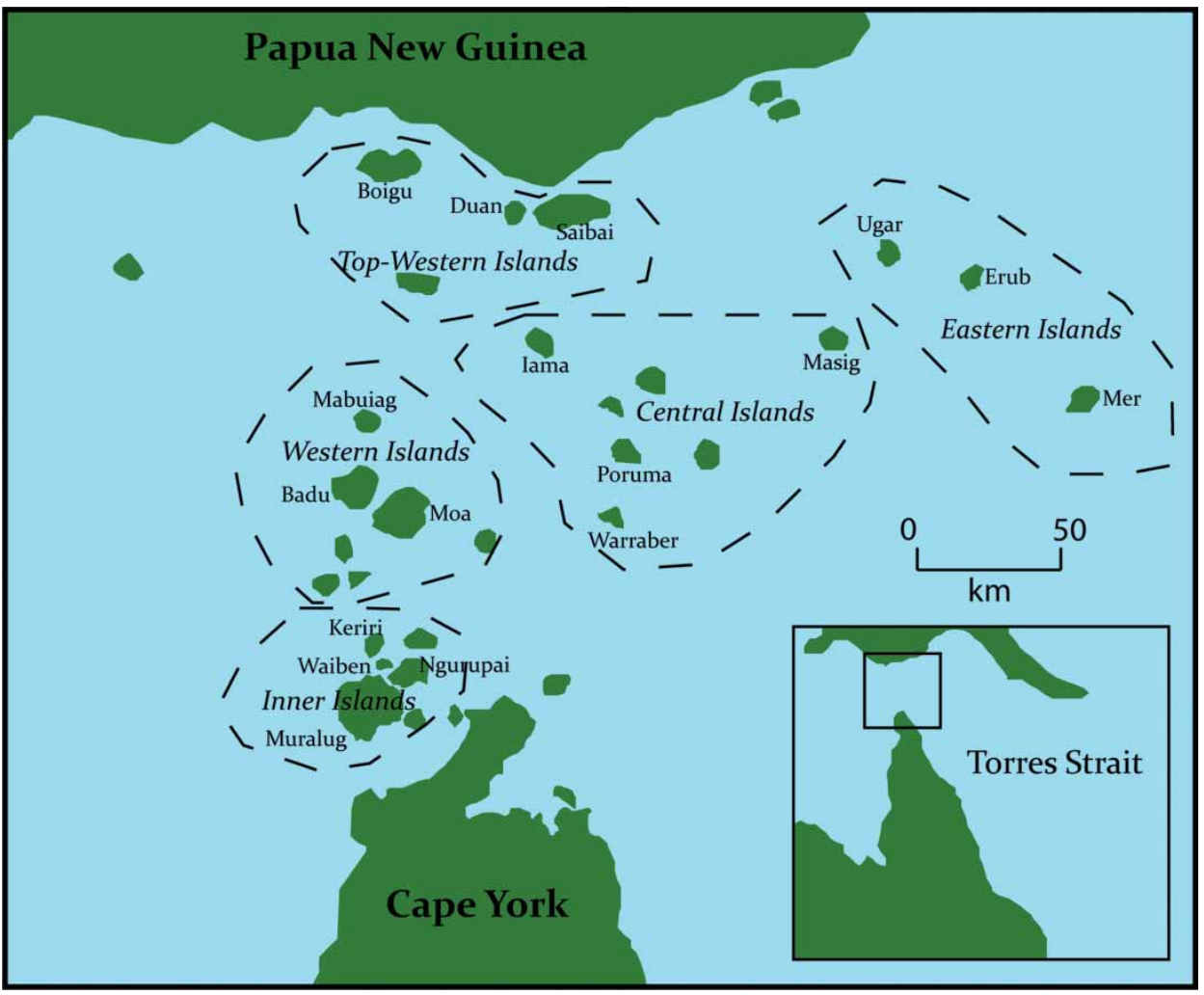

Figure 1. Map of Torres Strait.

\section{Climate science: climate change impacts in Torres Strait}

Direct impacts

There are a number of direct biophysical climate change impacts likely to occur in Torres Strait. As there is a significant degree of physical variation between islands, some of these impacts will be of greater significance than others. One of the most immediate concerns across the region, particularly for the six low-lying islands primarily located in the top western and central groups, relates to the effects of rising sea levels from slow onset sea level rise and increasing extreme weather events, leading to bigger storm surges (Duce et al. 2010, Green et al. 2010a).

Projecting sea level rise in Torres Strait is difficult. While there is great certainty in the scientific literature that sea levels will continue to rise, there is difficulty in projecting the amount of increase expected in this region specifically because of both the complex nature of tidal activity in the strait and lack of accurate bathometry and topographic data available (Green et al. 2010a). In addition, sea levels in the western Pacific region have risen faster than the global average for the last 17 years (SEAFRAME 2009). For this reason, it is important that the upper bounds of global average sea level rise predicted by the Intergovernmental Panel on Climate Change (IPCC) are not treated as an upper limit.

Air temperatures in the region are expected to increase similarly in the rest of coastal northern Australia, where the averages are projected to increase by about $1{ }^{\circ} \mathrm{C}$ by 2030 under both A2 and A1FI emission scenarios (Suppiah et al. 2010). While the air 
temperature in the region is important, the "apparent" temperature (an indicator of how the combination of air temperature, wind and humidity interact) provides more insight into how temperature increases will affect people's health. To put this in context, the annual apparent temperature in Torres Strait is approximately $10^{\circ} \mathrm{C}$ higher than the actual temperature (Suppiah et al. 2010). The Heat Stress Response Plan (Queensland Health 2010) specifies that an "extreme heat warning" be issued if the apparent temperature is expected to be higher than $40^{\circ} \mathrm{C}$ for more than two consecutive days. This warning indicates that the effects of increasing average temperatures pose a serious health concern in the Torres Strait region, as this apparent temperature threshold would be crossed on a regular basis during the wet season (December-May).

The projected change in rainfall suggests that average annual rainfall in the region is likely to increase by up to $6 \%$, with larger increases during the wet season (Suppiah et al. 2010). It is also expected that the intensity and variability of rainfall in the region will increase, which has implications for erosion and flooding as well as food production and water security. For islands like Warraber, where potable water is already in short supply, this means even further dependence on expensive, diesel-fuelled desalination plants.

\section{Indirect impacts}

The indirect impacts of climate change on the region must also be considered. These impacts include problems relating to an increase in fuel costs, which can, amongst other impacts, increase the cost of food. Both imported food (that is brought in by a weekly barge from Cairns), and traditional hunting and fishing activities (that need diesel fuel to run boats) would be affected by rising fuel prices (Green 2006). There is also an indirect impact on the health sector, through a likely increase in vector-borne diseases such as dengue, due to temperature and humidity change causing range change, which would significantly stress already stretched regional health services (Queensland Health 2010).

Torres Strait's unique border situation with Papua New Guinea adds to the complexity of predicting the severity of some indirect climate impacts. The Torres Strait Treaty, which formalises the significant cultural ties between Torres Strait Island communities and adjacent communities in Papua New Guinea, allows freedom of movement between treaty villages for cultural purposes. For this reason, it is likely that Papuans will continue to take advantage of the higher quality health services available in Torres Strait, thereby putting further strain on Australian resources. Many of the treaty villages (and surrounding villages in Papua New Guinea's Western Province) are already facing reduced availability of basic necessities, such as potable water. In addition, saltwater intrusion is having an increasingly detrimental effect on their ability to grow subsistence crops. Climate change is likely to exacerbate all of these issues.

This section has demonstrated that the visible, direct impacts from climate change are a significant concern for Torres Strait in the near future. However, the highly complex, and much less predictable, indirect climate impacts have the potential for far more severe consequences for the region due to, for example, complex, synergistic impacts and large uncertainties with respect to social and political organisations in neighbouring countries.

\section{Varying ways of prioritising climate impacts}

One area that scientific assessments of climate impacts tend to inadequately address, or give guidance about, is the different ways in which various climate impacts can be prioritised by 
Islanders and non-Islanders. Given the strong connection Islanders have between their cultural heritage and natural heritage (Fuary 2009a), Islanders are likely to prioritise the preservation of sacred sites. Areas containing rain stones or culturally significant trees, for example, are locations likely to remain unrecognised as important by western scientists. This prioritisation of cultural artefacts and locations does not deny the very real problem Islanders can see with maintaining basic services, such as sewerage. It does, however, imply there is a recognition that physical infrastructure can be rebuilt, which is not the case for damage to sacred sites or change to the lifecycle of totemic animals.

The response of Islanders and non-Islanders demonstrates how adaptation responses are likely to be prioritised differently. This situation is not unique to Torres Strait Islanders. For example, one concern regarding the indirect impacts of climate change in mainland Aboriginal communities is the worry that they may contribute to a perception that the community can no longer properly "look after" their land and sea country (Hunter 2009). A major concern in this case is that environmental changes understood by scientists as caused by climate change are not likely to be understood in the same manner by traditional owners. As a result, there is likely to be a significant effect on psychosocial health of the community due to their sense of obligation to look after their country. These kinds of issues, which are more likely to be considered "cultural" concerns, have not been well identified by western scientists or policy-makers to date in relation to responding to climate impacts.

\section{The apparent paradox of Warraber's refusal to allow more scientific research}

As the previous section has detailed, the impacts of climate change are a significant concern for all communities in Torres Strait. In spite of the strong scientific evidence that identifies this, a Councillor and an Elder from Warraber, one of the six "most affected" islands, issued a public refusal to support additional climate change research on their island in $2010 .^{1}$ It could be considered counterintuitive that a community in this region, particularly one located on a low-lying island such as Warraber, would take this position.

In the following section, we consider what community perceptions of scientific research are in order to better understand this situation. Specifically, we focus on the influence of past experience of scientific research in the region. Through this analysis, we argue that this history plays an important part in explaining the dynamics of present interactions between Torres Strait Islanders and scientific researchers in the region. This relationship is further explored in the fieldwork interviews in order to identify why the rejection of further scientific research on climate change was made.

\section{Methods}

The primary data for this research come from a series of semi-directive interviews conducted with Island leaders, policy-makers and community members $(n=40)$ obtained from five field trips in Torres Strait during 2006-2010 by Green and O'Neill, with additional material for Warraber obtained directly from the Island Councillor. The semidirective interview (Huntington 1998) was chosen due to its recognised suitability for recording Indigenous knowledge. Interview topics included: observations of environmental change, traditional knowledge of seasons and weather and past experience with scientific research. ${ }^{2}$ This information was supported with a documentary analysis of peer-reviewed and grey literature. Primary interview material provided detailed knowledge of the way Islanders understand and prioritise issues relating to environmental change, as well as an 
avenue to explore issues concerning the perceived frustration with how scientific research is conducted on the island more generally.

Preliminary field trips were focused on building relationships and conducting interviews, and for each trip a follow-up visit was conducted in order to "ground truth" results of the previous trip with participants. Emergent themes were identified through a text-based analysis of interview transcripts and video recordings, which sought to draw out common areas of concern across interviewees. Follow-up visits allowed for the verification of material, including discussion of important themes, and corrections to be made. This focus on a more collaborative approach recognises the differences between Indigenous knowledge and western science, while still helping to maintain accuracy of knowledge that is often difficult to translate outside of the cultural and environmental context it was developed in (Wilson 2001, Edwards et al. 2008).

\section{Background}

\section{Colonial history and outsider dominance of Islander affairs}

Torres Strait has historically been dominated by outsider, usually non-Islander, interests (Beckett 1987, Nakata 2004). This has influenced the way that Islanders engage with non-Islander researchers and bureaucrats, and provides significant insight into the context in which Islander communities still operate. Nakata, a Torres Strait Islander academic, analyses the history of the region and outside influences to find that there are three emergent spheres of influence that have dominated Islander affairs since contact: the state and federal government, the marine industry and the church and missionary organisations (Nakata 2004). These dominant influences were closely intertwined at times, as combined resources often exerted greater control over the region. As a result, Islander autonomy was often dictated by the disposition of a particular administrator towards Islanders (Nakata 2004). While government representatives held varying degrees of control over Islanders' private lives, such as access to wages or approval of marriages, social hierarchies established by the missionaries determined the levels of access to education and employment.

In a more recent paper, Nakata draws from his own experience to illustrate the relationship between Islanders and non-Islanders in the context of managing marine resources in the region (Nakata 2010). In one exchange, Nakata recalls his uncle "growling" at him for making a decision during a hunt he perceived to have been informed by "that talk coming into our community from "outside"" (Nakata 2010, p. 54). The emphasis on the issue of "outside" knowledge not being allowed to influence decision-making in the community is an indication of the heightened level of frustration felt towards the prevalence of non-Islander perspectives in the region - and the level of influence they have in shaping everyday life. While colonial influences have evolved significantly over time, it is clear that there are elements of these structures that have maintained a dominant status in regional affairs today. This colonial history has a significant influence in defining the way in which Indigenous communities engage with researchers.

\section{Experience of scientific research in Indigenous communities}

In many Indigenous communities, research often stirs up emotions of mistrust and anger because it is deeply linked to the colonial experience, meaning that it "is probably one of the dirtiest words in the indigenous world's vocabulary" (Smith 1999, p. 1). The 
dominance of outsider views within Indigenous communities is not limited to Torres Strait, and in mainland Aboriginal communities, this has largely been attributed to the fact that up until recent years, "research conducted in Aboriginal lands was done without permission, consultation, or involvement of Aboriginal people" (Martin and Mirraboopa 2003, p. 203). Scientific research in Australia has been described as "terra nullius research" because it was often undertaken without the involvement, permission or consultation of Indigenous communities. The concern around scientific research carried out in this tradition is that it often presents Indigenous Australians as "objects of curiosity and subjects of research" (Martin and Mirraboopa 2003, p. 203), failing to fully recognise the value and significance of their culture and way of life.

The flow of information from research and official bodies back to the communities has been highlighted as a critical issue in Torres Strait for over 20 years (Mulrennan 1992, Arthur 2007). This has led to the creation of two documents that explicitly discuss crosscultural research concerns in Torres Strait (QATSIP 1999, Fuary 2009b), but it appears that many of the issues they raise have not been carried over into scientific research. Prior to Warraber's refusal for more scientific research on climate change, a comprehensive review of the Torres Strait Cooperative Research Centres (CRC), ${ }^{3}$ noted that mechanisms for disseminating results were generally considered to be inadequate, raising concerns over tensions that had arisen in relation to poor communication of research aims in some projects (Arthur 2007).

Similar issues relating to the communication of research findings in Australian Indigenous communities have also been documented by larger research institutions, such as the Australian Institute of Aboriginal and Torres Strait Islander Studies (AIATSIS 2011) and the National Health and Medical Research Council (NHMRC 2006). Both these bodies have developed Indigenous engagement protocols and research practices, but despite these attempts to reframe the way in which research is conducted in Indigenous communities, there is significant cause for concern that these guidelines are not always followed. Experiences where research in Indigenous communities is repetitive, or poorly constructed or integrated or aligned with community needs, make it less surprising when Indigenous scholars generally criticise their experience with researchers from outside their community as not being mutually beneficial (Smith 1999, 2005, Martin and Mirraboopa 2003, Nakata 2004, Sherwood 2010). On the whole, there appears to be a common concern that scientific research undertaken in Indigenous communities systematically fails to understand important community objectives due to an ongoing lack of collaboration at the outset of identifying research objectives.

This contextual background presented above highlights two key points: first that both historical and contemporary experiences show the ongoing relevance of a colonial legacy, which will inevitably influence the way that Islanders respond to non-Islander ideas; second that Indigenous experience with scientific researchers, both in Torres Strait and in Australia more widely, demonstrates a need to reframe research so that it does not continue on the same ineffective track. Here, it begins to seem more reasonable that, at the community level, Islander leaders are not likely to want to take on the advice of "outsider" scientists or policy-makers unless it is clearly demonstrated to be in line with their community's interests and priorities. It does not, however, clearly explain why such a strong rejection was made of scientific research on a topic likely to be of such importance for these communities.

The following section outlines the fieldwork results, which places an emphasis on understanding the way that Islanders view and prioritise the problems posed by climate change. 


\section{Results}

The interviews demonstrate that there are a number of shared concerns that are relevant to Warraber's refusal to allow more scientific research. These concerns include community frustration with scientific research, a lack of tangible results from previous research efforts and concern over a disregard for cultural impacts. Perhaps more significantly, many of the issues that were raised in the interviews have clearly been documented for a number of years. In the following section, we present the emergent themes arising from the interviews and a discussion of them in the context of the documentary analysis.

\section{Emergent themes}

\section{Inaction}

The problem of inaction was an important emergent theme from the majority of people interviewed during fieldwork. Despite the loss of metres of shoreline, beach and trees in a number of communities, there has been little investment by the state or federal government to prevent further damage. This inaction has contributed to significant levels of frustration in many communities, which is explained in the following excerpt:

\footnotetext{
I guess I'm frustrated that this issue of erosion was brought up years ago, and we're still talking about it. It always seems to be ... the government seems to be putting it in the hard basket each time we talk about it. It's so frustrating having to repeat it each time, and every time you talk to different people ... and we're talking about the same issue. And it's just been put on hold, put on hold each time. It's like, no one wants to discuss it. It's like, wait til something bad happens - then we'll talk about it (IW12.29.01.2010).
}

As a result, many communities have taken the initiative to build coastal defences themselves, by making use of whatever resources they have available. For example, the coral cay islands in the central group, where rocks are scarce, have made use of tractor tyres, tree trunks and concrete rubble to create semi-permanent sea walls. Warraber's Community Forum has prohibited driving close to sand dunes and other areas with high erosion potential to further reduce impacts. Traditional knowledge of sand stabilisation techniques are also being employed, with both Poruma and Warraber presently engaged in projects supporting revegetation in erosion-prone areas, and avoiding clearing vegetation wherever possible (Green and Lui 2010, Green and Mosby 2010). Some of these projects have been ongoing for several years, and most are informed primarily by traditional knowledge or cultural practices (Figure 2).

\section{Cultural erosion}

The emergent theme of cultural erosion was particularly prominent amongst the elders interviewed. Nearly every Islander interviewed expressed a concern that directly relates to cultural erosion. Some of the issues raised included: an observed change in the abundance and location of totemic marine animals, such as turtle and dugong; an increase in the severity of erosion events, which has impacted on culturally significant sites such as cemeteries; and high tides encroaching on sites where traditional foods such as gassi (wild potato) and mud crab were once collected (EW1-5. IW6-12.12-17.07.2010). One of the elders on Warraber recalled one particularly severe erosion event where a number of the graves in the cemetery were washed out (EW2.16.07.2010), and most community members spent the day collecting their ancestors remains in order to re-bury them. 


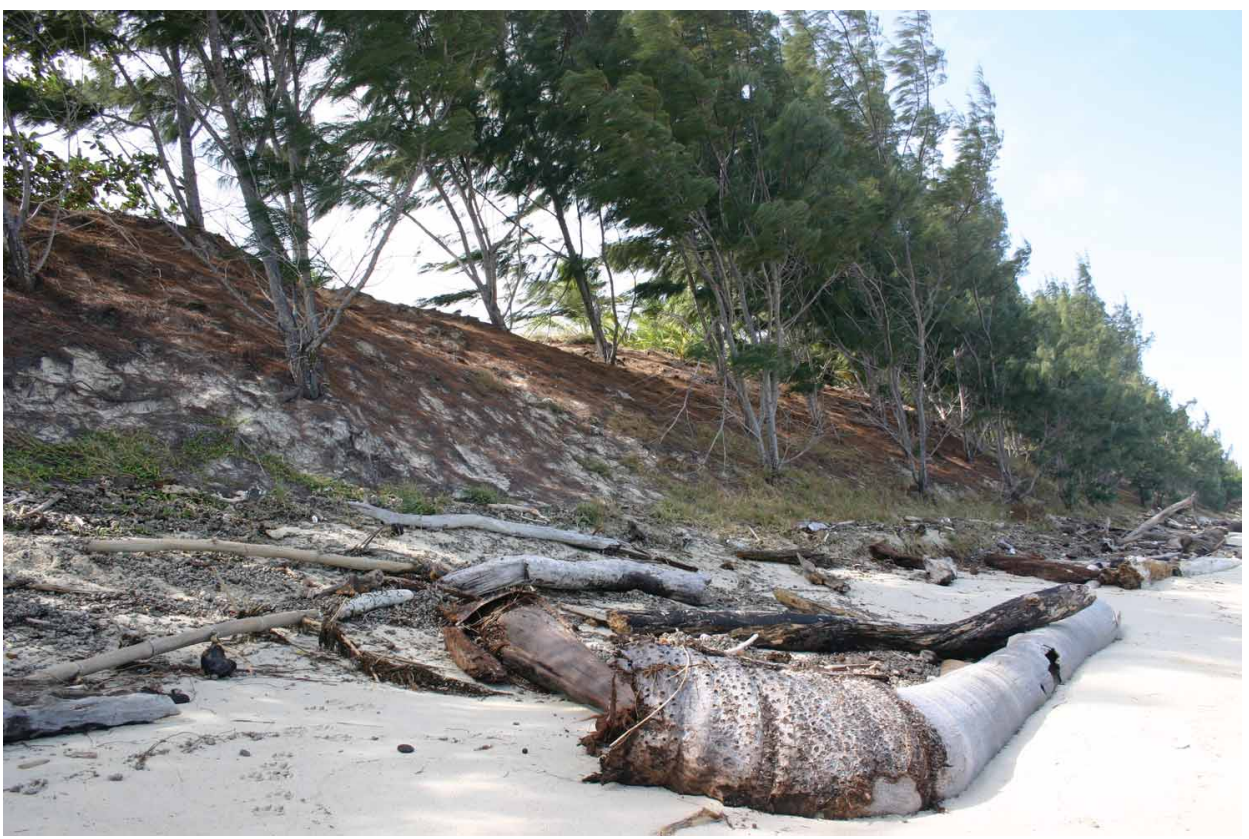

Figure 2. Revegetation and sand dune stabilisation work on Poruma.

Responding to cultural erosion from climate change is not listed in the regional climate change strategy as a priority issue (TSRA 2010), which indicates that the top-down approach to climate change has not primarily been informed by Islander priorities. Torres Strait Islanders are not alone in this concern, as cultural erosion has also been raised as a priority issue in mainland Aboriginal communities. In Kakadu National Park, for example, this is reflected in policy documents that explicitly state "cultural expression would appear to be directly threatened by climate change" (Director of National Parks 2010, p. 5).

\section{Failure to consider local knowledge}

Analysis of the interviews also identified an emergent theme that local knowledge is not considered significant in identifying changes in the environment, or developing policies to build community resilience to climate change. To some participants, this was a critical point of contention, as Torres Strait Islander knowledge has informed Islander decisions in responding to environmental change at the community level for thousands of years. One participant likened the disconnect between decision-makers and community members as if the decision-makers were "on top of a mountain" (EW2.16.07.2010), citing frustration that communities have little way of knowing how or why decisions were being made.

Participants identified a range of examples in which they felt Islander knowledge was not properly considered. Several elders from Warraber raised the issue that they are currently grappling with coastal erosion, remarking that local observations have largely been ignored in scientific assessments. Warraber has three areas of concern in regard to erosion. The first priority area, according to both the results of our fieldwork interviews and the regional climate change strategy (TSRA 2010), is at the eastern end of the sea 
wall that runs across the north side of the island. The other two areas are at the southern end of the island: one concerns a low-lying area near the resort and the second concerns a cluster of Wongai trees near the dam. One of the elders described this cluster of Wongai trees smol Warraber, which was once a place that families would come to digging for sand crabs and traditional foods such as gassi (wild potato). Over the past 50 years, they have watched the high tide mark encroach on smol Warraber, which has significantly reduced the number of Wongai trees in the area. There are now only a handful of trees left, and families no longer dig for mud crabs on the beach in this area (EW3.10.08.2009). Despite these observations, an assessment of options for managing erosion ranks the area near the Wongai trees as a low priority, stating that concern over the loss of Wongai trees "should not be of concern" (Parnell 2006, p. 6).

\section{Mistrust}

In addition to frustration over the need for further scientific "proof" that climate change is a pressing concern, another emergent theme arising from the interviews was that many Islanders are worried that the failure to undertake critical adaptation measures, such as upgrading sea walls, indicates that an off-Island relocation policy is the ultimate, if unstated, goal of the federal government.

This high level of mistrust implies that there are serious issues with communication between government organisations and community members, which is not dissimilar to cross-cultural communication issues, particularly of scientific research, that have been previously documented. Echoing concerns raised in (Mulrennan 1992, Arthur 2007) one participant pointedly remarked "We only see people go, people come, people go-there's no paper" (EW2.16.07.2010).

The problems of scientific researchers, and other outsiders, coming into Torres Strait Islander communities for short periods of time for limited benefit to the community has become a frequent enough occurrence that the practice has been named. Islanders call these people "seagulls" due to their ability to "fly through the Strait making a lot of noise about local concerns, and fly off without doing anything to help" (IW13.20.02.2010). Recognition of this problem at a national, and international, level suggests that concerns raised by Torres Strait Islanders in the literature, and in our interviews, are not unique. For example, the Mãori in Aotearoa (New Zealand) use the expression harore rangitahi, a "one-day mushroom" to describe scientific researchers, a reflection on the experience of scientists "not being committed to long term community goals" (Allen et al. 2009, p. 241).

\section{Documentary analysis}

\section{Top-down approach to adaptation}

The Torres Strait Regional Authority (TSRA) has developed a regional plan for responding to the climate change (TSRA 2010). In addition to the regional climate change strategy, Islander-identified priorities can be seen in climate change impact documents for Poruma, Saibai and Warraber (Green 2010, Green and Lui 2010, Green and Mosby 2010). The Torres Strait Climate Change Strategy (TSRA 2010) identifies a number of adaptation measures that could be implemented in some of the communities that are at greater risk from climate impacts. For most of the six low-lying islands, repairs and or upgrades to existing protective infrastructure such as sea walls are priority adaptation activities (TSRA 2010), as existing "hard engineering" protective measures are in varying states 
of disrepair. Other activities suggested in the report include enhancing the understanding of "risk" science and local options for mitigation (TSRA 2010, p. 13).

One of the suggestions includes a need to anticipate the impact of bigger storm surges by raising houses and some public buildings on stilts (TSRA 2010). Interestingly, building raised dwellings was a common practice until relatively recently. Only when government funding became the main source of money to build houses were they built directly on the ground. This change in building practice occurred to save money on up-front building costs. The initial cost savings from this decision proved to be very short-term though, as all of the houses on Saibai and Boigu have since had to be raised on steel piles, at considerable cost (Green et al. 2009) (Figures 3 and 4).

\section{Barriers to implementation: financial support}

One of the most significant barriers to implementation of the most pressing concerning adaptation activities is a general lack of financial support (TSRA 2010). Although an exact costing is not included in the TSRA's climate change strategy, follow-up interviews indicate that the priority measures outlined in it would cost approximately $\$ 24$ million. This support is yet to be forthcoming, despite a visit in May 2010 from the then Climate Change Minister, Penny Wong.

Minister Wong did announce financial support during her visit, including \$1 million to install tide gauges to monitor sea level rise, along with $\$ 400,000$ to support additional scientific research into climate impacts (Wong et al. 2010). The promise of monitoring an already documented problem and continuing to do more scientific research was met with resistance in some Torres Strait communities. Community leaders from the central

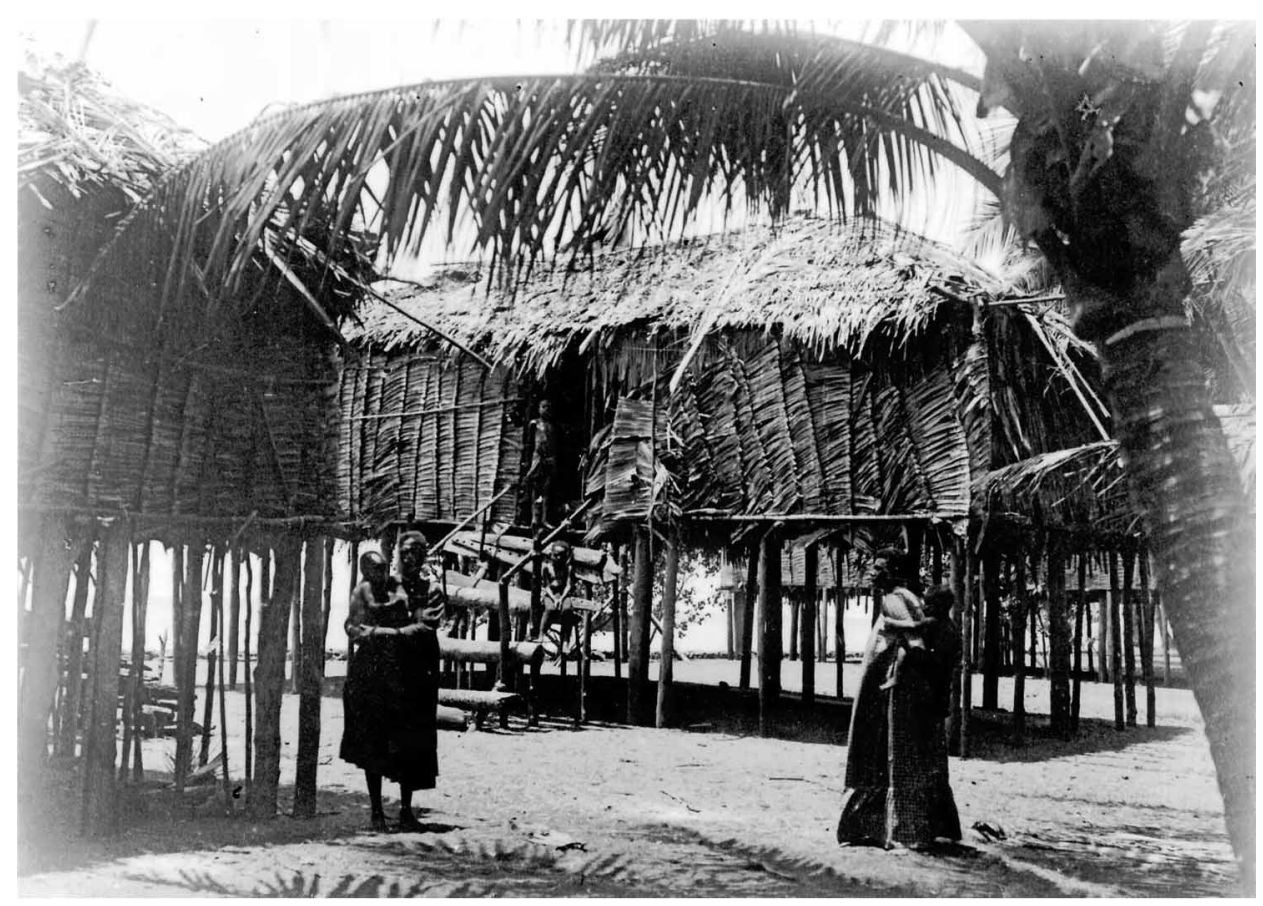

Figure 3. Traditional house on Saibai. Reproduced by permission of University of Cambridge Museum of Archaeology \& Anthropology (P.1066.ACH1). 


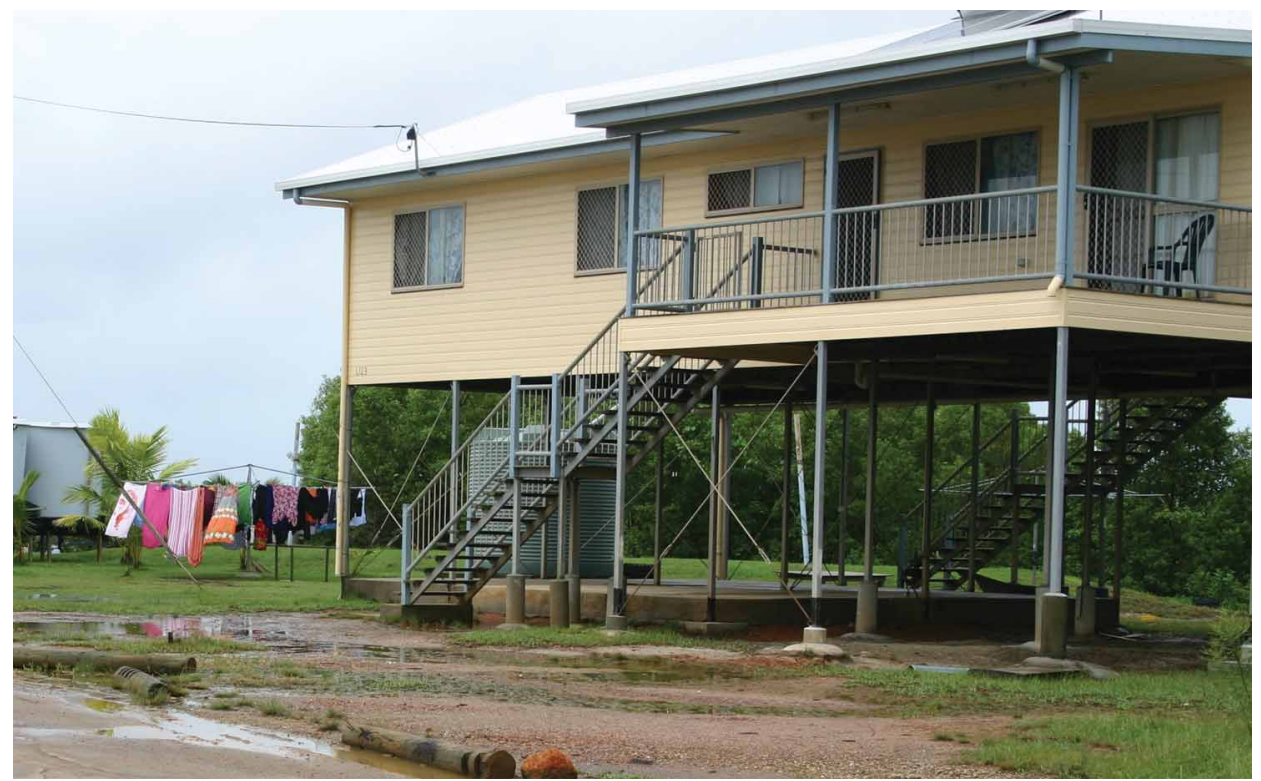

Figure 4. New raised house on Saibai.

islands have been lobbying for support to upgrade and improve their sea walls since 2000 (EW1.16.07.2010). However, this was not the first time that this issue was documented. Six years ago, concerns that local sea levels appeared to be increasing were raised in official documents (Mulrennan et al. 1994). Acting on prior recommendations, as opposed to conducting more scientific research, has been on the Councillors' lobbying agenda for over 10 years (Mulrennan et al. 1994, Hennessy et al. 2007).

Further financial support for some of the initiatives outlined in the TSRA climate change strategy was put forward as a Private Members Bill in August 2011. The Bill, which was passed with bipartisan support, committed to "restore and rebuild the damaged sea walls on the outer islands of the Torres Strait to protect island communities from further devastation" (Entsch 2011). The passing of the Torres Strait Sea Walls Bill suggests that the federal government recognises that it has a responsibility to financially support adaptation measures. However, only 3 months after this bill was approved, the Federal Minister for Regional Australia, Simon Crean, reversed the decision, claiming the sea walls were a State government responsibility. This cycle of promising funding and then failing to deliver is, unfortunately, a very regular occurrence in Australian Aboriginal and Torres Strait Islander communities.

\section{Summary}

Warraber Islanders' public refusal to support more scientific research raises two important points: first that Islanders' experience demonstrates that "doing more research" frequently gets in the way of actually undertaking activity on the ground, that is, it is seen by Islanders as a stalling mechanism; secondly, and arguably more important in the discussion of how to make climate change research more relevant in this context, that Islander knowledge is often ignored or at best demoted in order to carry out even more "scientific" research. The TSRA regional approach to climate change adaptation recognises that traditional 
knowledge plays a role in understanding local impacts, but the identified action plan says little to suggest that their traditional knowledge may have a more significant role to play in prioritising adaptation activities.

Despite the fact that local concerns over climate impacts are obviously well-documented, funding to enable most of the suggested activities has not yet been forthcoming from either the federal or state government. TSRA policy documents and discussions with TSRA staff indicate that relocation is not currently an option for discussion (TSRA 2010), but in order avoid making short-sighted and ultimately costly decisions, this issue must be openly discussed if it is indeed being given consideration within government. There are climate impacts that would benefit from further scientific research in order to enhance the understanding of how they will affect communities in the longer term. However, the above examples also indicate that the level of frustration felt within communities over inaction over existing documented climate impacts appears, in this respect, to be justified.

\section{Discussion}

Scientific research can play a critical role in informing the development of adaptation policy in response to direct and indirect impacts from climate change. While uncertainty regarding specific climate impacts has been used as a primary reason to undertake more scientific research, the examples given above demonstrate that drawing from Islander knowledge could have avoided a number of expensive mistakes. This situation creates tension between Indigenous knowledge holders and western scientists, which we suggest in this instance to be demonstrated by Warraber's refusal to support more scientific research on climate change.

In recent years, there have been some attempts by scientists and policy-makers to recognise the value of incorporating Indigenous knowledge into adaptation strategies for practical, cultural and methodological purposes (Green et al. 2010b). While some of this information may be accessible through oral histories, there is increasing recognition that Indigenous knowledge should also inform methodological considerations - as it contains knowledge both of what to look for as well as how to look for it. A good example of this in an Aboriginal Australian context can be found in Ngurra-kurlu: a way of working with Warlpiri people, which informed the methods for Homes' $\mathrm{PhD}$ research on Warlpiri ecological knowledge (Pawu-Kurlpurlurnu et al. 2008, Holmes 2010).

In order to further explore ways to mitigate this problem, the following section provides a discussion on Indigenous knowledge, specifically its relevance in the context of climate change research. We argue that the results from our interviews raise issues that are consistent with much of the international literature discussing the applications of Indigenous knowledge to climate change research. The emergent themes from our interviews also point to the need to reframe the way scientific research occurs in Islander communities.

\section{Indigenous knowledge systems}

In an international context, Indigenous knowledge has been shown to be valuable to understand and address the impacts of climate change on a number of levels. For the purposes of this discussion, we use the definition of Indigenous knowledge to be "a cumulative body of knowledge, practice and belief, evolving by adaptive processes and handed down through generations by cultural transmission, about the relationship of living beings (including humans) with one another and their environment" (Berkes 2008, p. 7). 
The value of Indigenous knowledge as a resource to inform development initiatives has some precedent. In the 1950s and 1960s, development theorists largely regarded Indigenous or traditional knowledge as "inferior" and "inefficient" (Agrawal 1995). However, by the 1990 s, Indigenous knowledge was regularly discussed in the context of sustainable resource use and development studies, with the suggestion that Indigenous knowledge allowed its holders to exist in harmony with their natural environment (Agrawal 1995). This is largely attributed to the highly contextual and locally specific nature of Indigenous knowledge. In Australia, Indigenous ecological knowledge in particular is well-recognised for its valuable contribution to improved natural resource management outcomes (Prober et al. 2011).

In western worldviews, there is a distinct boundary between social and ecological systems. Indigenous knowledge systems do not share this distinction, which suggests that they are potentially well-placed to provide critical insight into the links between what scientists see as two systems and how they might interact with each other (Berkes 2008). There is a particular benefit to this synergistic relationship in understanding and responding to the impacts of climate change. For example, it can provide insight into important relationships between environmental degradation, cultural erosion leading to problems with the psychosocial health of individuals and overall community resilience and wellbeing. These insights are not currently well understood in Torres Strait or, for that matter, in mainland Aboriginal communities.

From a policy perspective, properly considering the value of Indigenous knowledge can help to ensure that adaptation measures are effective and appropriate in the local context. In Australia, it has been recognised that "the most effective adaptation strategy may be ineffective if there are counter values and cultural norms that preclude its implementation" (NCCARF 2009). Thus, by drawing from Indigenous knowledge in planning for adaptation, policy-makers can also proactively seek to understand potential counter values and cultural norms that may challenge the adaptation process. In a broader framework, the act of including Indigenous knowledge in scientific assessments or government planning strategies indicates a shift towards more respectful and inclusive means of addressing community concerns.

International scientific organisations are increasingly recognising the importance of Indigenous knowledge. For example, Chapter 20 in the IPCC Fourth Assessment Report notes that climate change policy "requires the inclusion of local knowledge, including Indigenous knowledge, to complement more formal technical understanding generated through scientific research" (Yohe et al. 2007, p. 832). Regional studies of climate impacts, notably the Arctic Climate Impact Assessment, are also increasingly recognising the need to include Indigenous knowledge (Huntington and Fox 2005). Recent work in the Arctic has also identified the insight provided by Indigenous knowledge adds significant depth to the analysis of scientific observations that would otherwise be lacking (Weatherhead et al. 2010).

\section{Reframing methods}

This increasing level of interest in the value of Indigenous knowledge has led scholars to suggest that there are both practical and ethical concerns to consider in developing projects investigating the links between Indigenous knowledge and western science. In the Pacific, for example, Lefale (2010) suggests that multidisciplinary collaboration would be particularly beneficial to research of this nature, as scientists are not necessarily well-trained in methods of collecting qualitative data, and social science approaches would help navigate differences in culture, custom and language. 
While Islander and non-Islander ways of prioritising the impacts of climate change may identify different areas of concern, results from this research suggest that both perspectives suggest that climate change adaptation is an immediate concern. By reframing research methods, more inclusive ways of identifying Islander priorities would be facilitated. As we have demonstrated in the previous section, a non-Islander's perspective prioritises the more "visible" economic costs of coastal inundation to low-lying infrastructure such as roads, council buildings or water reticulation services. The non-Islander perspective neglects the cultural damage caused by, for example, the erosion of coastal sacred sites, or changing marine species' abundance caused by increasing sea surface temperatures.

Past studies about improving climate impact assessments have noted the challenges that different worldviews pose to traditional scientific methods and demonstrate there is a need to "encompass alternative visions for existing and future environments" (Braaf 1999, p. 99). In acknowledgement of this problem, the following section discusses possible ways of undertaking research that responds to the need for enhanced cooperation and collaboration with Torres Strait communities.

\section{Indigenous research methods}

Policy-makers' preference for quantitative data to inform decision-making is not the only barrier to including Indigenous knowledge in climate change adaptation planning. The positivist nature of science does not easily accommodate recognising and working in conjunction with systems that are based on a different epistemological foundation. However, given the significant lack of observational data for the region with which to work, it is important to consider other ways of collecting and compiling data sets. There is an international trend towards actively engaging with Indigenous knowledge on the topic of climate change. However, the recent events in Torres Strait outlined previously demonstrate that engagement with Indigenous knowledge by scientists and policy-makers in Torres Strait is limited.

Historical experience in Torres Strait demonstrates that a more collaborative approach clearly has advantages. It would help practitioners ensure that adaptation measures are locally relevant, culturally appropriate, and that they respond to important cultural and socio-economic concerns. Indigenous scholars have long been advocating such an approach, which is often referred to as Indigenous research methodologies (IRM).

IRM act as a framework to provide methods that emphasise how past (and present) events may shape community sentiments. The critical difference between the focus of IRM and traditional scientific research is that a significant level of collaboration between researchers and communities is paramount at all stages of the IRM research process (Smith 2005, Sherwood 2010). IRM research endeavours suggest that new research must be aware of, and respond to, past injustices if effective research relationships are to be developed (Smith 1999).

\section{Conclusion}

The direct and indirect impacts of climate change in Torres Strait are significant. Undertaking adaptation activities to reduce these impacts is a critical local priority. However, a significant level of collaboration between Islanders, scientific researchers and policy-makers is necessary to prioritise responses in order to build community resilience to these already identified impacts. To date, this process has not occurred. The lack of engagement of scientific researchers with local knowledge holders is a significant problem that has emerged 
from this research. This situation can be clearly seen in the case of Warraber, where in order to stop the cycle of more funds being put into "more" scientific research - rather than funding already identified adaptation activities - community leaders have taken the unusual step of preventing further climate research to be undertaken on their Island.

The historical context of their decision is important, because it amplifies the frustration Islanders feel over previous failures by state and federal government bodies to provide adequate financial support for previously identified adaptation initiatives and further to disregard the consideration of local knowledge in regional planning and development strategies. Framed within the contextual history of non-Indigenous researchers working in Torres Strait, Islander leaders' concerns about new scientific research activities are less surprising. Perhaps more importantly, this problem, and the Island leaders' response is consistent with the experience of other Indigenous communities in Australia, which indicates it may be appropriate to draw from the experience of other Indigenous communities to address this issue in Torres Strait.

Our results have shown that engaging with Indigenous knowledge holders in a way that their priorities are clearly reflected in policy could reduce current levels of apprehension and mistrust of government bodies at the community level. It can also contribute to a better understanding of some of the more complex indirect impacts of climate change. This is particularly true of the indirect cultural impacts, which have not been well identified to date.

Further, both national and international experience of climate scientists working in remote Indigenous communities suggest that there is still much to be learned about past changes and adaptive capacity that can be drawn from local Indigenous knowledge. In order to inform future climate-related scientific research, however, including this knowledge will require a significant reframing of the way scientific research is undertaken. In order to redress this situation, we suggest that future scientific research could use IRM frameworks which would reduce the occurrence of problems by enhancing local involvement in all stages of the research, planning and policy-making processes.

\section{Acknowledgements}

The authors would like to acknowledge the generous contributions of time and knowledge from Warraber community members that formed the base for this research. In addition, we would like to thank our two anonymous reviewers for their constructive feedback, which has much improved this paper. This research was conducted with the support of funding from the Adaptation Research Network for Marine Biodiversity and Resources (CO), and from the Australian Government's Marine and Tropical Sciences Research Facility (DG).

\section{Notes}

1. "Warraber is taking a stand, and will not accept any more research for Climate Change" (Torres News 2010).

2. Ethical approval was received from the Human Research Ethics Committee at the University of New South Wales, approval numbers: 09024 and 10139.

3. CRC are major federal government initiatives, established with the aim of delivering specific outcomes that respond to end-user needs.

\section{References}

Agrawal, A., 1995. Dismantling the divide between indigenous and scientific knowledge. Development and Change, 26 (3), 413-439. 
AIATSIS, 2011. Guidelines for ethical research in Australian indigenous studies. Canberra: Australian Institute of Aboriginal and Torres Strait Islander Studies.

Allen, W., et al., 2009. Kia pono to mahi putaiao - doing science in the right spirit. Journal of the Royal Society of New Zealand, 39 (4), 239-242.

Arthur, B., 2007. An assessment of the CRC Torres Strait: 2003-2007. Canberra: CRC Torres Strait.

Beckett, J., 1987. Torres Strait islanders: custom and colonialism. Cambridge, MA: Cambridge University Press.

Berkes, F., 2008. Sacred ecology. 2nd ed. New York: Routledge.

Braaf, R.R., 1999. Improving impact assessment methods: climate change and the health of indigenous Australians. Global Environmental Change, 9 (2), 95-104.

Director of National Parks, 2010. Kakadu national park climate change strategy 2010-2015. Canberra: Department of Environment, Water, Heritage and the Arts.

Duce, S.J., et al., 2010. A synthesis of climate change and coastal science to support adaptation in the communities of the Torres Strait. Cairns: Reef and Rainforest Research Centre Limited.

Edwards, K., et al., 2008. Trust the process: community-based researcher partnerships. Pimatisiwin, $6(2), 187-199$.

Entsch, W., 2011. Torres Strait Island Sea Walls [online]. Warren Entsch MP. Available from: http:// www.warrenentsch.com.au/Portals/0/Files/MOTION - Torres Strait Sea Walls.pdf [Accessed 31 May 2012].

Fuary, M., 2009a. Reading and riding the waves: the sea as known universe in Torres Strait. Historic Environment, 22 (1), 32-37.

Fuary, M., 2009b. An evaluation of previous and current methods and models for researching Indigenous resource use and purposes, with recommendations for "best practice" research solutions. Cairns: Reef and Rainforest Research Centre Limited.

Green, D., 2006. How might climate change affect island culture in the Torres Strait? Aspendale, VIC: CSIRO Marine and Atmospheric Research.

Green, D., 2010. Building resilience to climate change impacts on Saibai, Torres Strait [online]. Report to the Marine and Tropical Sciences Research Facility. Available from: http:// torresstraitclimate.org/ [Accessed 16 February 2011].

Green, D. and Lui, W., 2010. Building resilience to climate change impacts on Warraber, Torres Strait [online]. Report to the Marine and Tropical Sciences Research Facility. Available from: http:// torresstraitclimate.org/ [Accessed 16 February 2011].

Green, D. and Mosby, P., 2010. Building resilience to climate change impacts on Poruma, Torres Strait [online]. Report to the Marine and Tropical Sciences Research Facility. Available from: http://torresstraitclimate.org/ [Accessed 16 February 2011].

Green, D., Jackson, S., and Morrison, J., 2009. Risks from climate change to Indigenous communities across the tropical north of Australia. Canberra: Department of Climate Change and Energy Efficiency.

Green, D., et al., 2010a. An assessment of climate change impacts and adaptation for the Torres Strait Islands. Australia, 102 (3-4), 405-433.

Green, D., Billy, J., and Tapim, A., 2010b. Indigenous Australians' knowledge of weather and climate. Climatic Change, 100 (2), 337-354.

Hennessy, K., et al., 2007. Australia and New Zealand. In: M.L. Parry, O.F. Canziani, J.P. Palitikof, J. van der Linden, and C.E. Hanson, eds. Climate change 2007: impacts, adaptation and vulnerability. Contribution of working group II to the fourth assessment report of the Intergovernmental Panel on Climate Change. Cambridge, MA: Cambridge University Press, 507-540.

Holmes, M., 2010. Law for country: The structure and application of Warlpiri ecological knowledge. Thesis $(\mathrm{PhD})$. University of Queensland.

Hunter, E., 2009. Radical hope' and rain: climate change and the mental health of Indigenous residents of northern Australia. Australasian Psychiatry, 17 (6), 445-452.

Huntington, H.P., 1998. Observations on the utility of the semi-directive interview for documenting traditional ecological knowledge. Arctic, 51 (3), 237-242.

Huntington, H.P. and Fox, S., 2005. The changing arctic: indigenous perspectives. In: C. Symon, L. Arris, and B. Heal, eds. Arctic climate impact assessment. Cambridge, MA: Cambridge University Press, $1-38$.

Lefale, P.F., 2010. Ua 'afa le Aso stormy weather today: traditional ecological knowledge of weather and climate. The Samoa experience. Climatic Change, 100 (2), 317-335. 
Martin, K.L. and Mirraboopa, B., 2003. Ways of knowing, ways of being and ways of doing: a theoretical framework and methods for Indigenous re-search and Indigenist research. Journal of Australian Studies, 27 (76), 203-214.

Mulrennan, M., 1992. Coastal management: challenges and changes in the Torres Strait Islands. Casuarina, NT: North Australia Research Unit, Australian National University.

Mulrennan, M., Hanssen, N., and ICC, 1994. Marine strategy for Torres Strait: policy directions. Australia: Australian National University North Australia Research Unit and the Torres Strait Island Coordinating Council.

Nakata, M., 2004. Commonsense, colonialism and government. In: R. Davis, ed. Woven histories, dancing lives: Torres Strait islander identity, culture and history. Canberra: Aboriginal Studies Press, 154-173.

Nakata, M., 2010. The cultural interface of islander and scientific knowledge. Australian Journal of Indigenous Education, 39 (Supplement), 53-57.

NCCARF, 2009. National climate change adaptation research plan: marine and biodiversity resources. Hobart: National Climate Change Adaptation Research Facility.

NHMRC, 2006. Keeping research on track: a guide for Aboriginal and Torres Strait islander peoples about health research ethics. Canberra: National Health and Medical Research Council.

Parnell, K., 2006. Rapid assessment of shoreline erosion and management recommendations. Report submitted to the Torres Strait Regional Authority. Cairns: James Cook University.

Pawu-Kurlpurlurnu, W.J., Holmes, M., and Box, L., 2008. Ngurra-kurlu: A way of working with Warlpiri people. DKCRC Report 41. Desert Knowledge CRC, Alice Springs.

Prober, S., O’Connor, M., and Walsh, F., 2011. Australian Aboriginal peoples' seasonal knowledge: a potential basis for shared understanding in environmental management. Ecology and society, 16 (2), $1-16$

QATSIP, 1999. Mina mir lo ailan mun. Brisbane: Department of Aboriginal and Torres Strait Islander Policy and Development.

Queensland Health, 2010. Dengue fever in North Queensland [online]. Dengue fever in north Queensland. Available from: http://www.health.qld.gov.au/dengue/ [Accessed 27 January 2011].

SEAFRAME, 2009. Pacific country report - sea level \& climate: their present state. South Pacific Sea Level and Climate Monitoring Project, Niue.

Sherwood, J., 2010. Do no harm: decolonising Aboriginal health research. Doctoral Thesis. The University of New South Wales.

Smith, L.T., 1999. Decolonising methodologies: research and indigenous people. London: University of Otago Press.

Smith, L.T., 2005. On tricky ground: researching the native in the age of uncertainty. In: N.K. Denzin and Y.S. Lincoln, eds. Sage handbook of qualitative research. Thousand Oaks, CA: Sage Press, 85-107.

Suppiah, R., et al., 2010. Observed and future climates of the Torres Strait region. Aspendale: CSIRO Marine and Atmospheric Research.

Torres News, 2010. Warraber takes stand on climate change. Torres News. 13 November.

TSRA, 2010. Torres Strait climate change strategy 2010-2013. Thursday Island: Torres Strait Regional Authority.

Weatherhead, E., Gearheard, S., and Barry, R.G., 2010. Changes in weather persistence: insight from Inuit knowledge. Global Environmental Change-Human and Policy Dimensions, 20 (3), 523-528.

Wilson, S., 2001. What is an indigenous research methodology? Canadian Journal of Native Education, 25 (2), 175-179.

Wong, P., Macklin, J., and Turnour, J., 2010. Assisting Torres Strait communities with the impacts of climate change [online]. Australian Government. Available from: http://www.climatechange.gov. au/ [Accessed 4 June 2012].

Yohe, G.W., et al., 2007. Perspectives on climate change and sustainability. In: M.L. Parry, O.F. Canziani, J.P. Palitikof, P.J. van der Linden, and C.E. Hanson, eds. Climate change 2007: impacts, adaptation and vulnerability contribution of working group II to the fourth assessment report of the Intergovernmental Panel on Climate Change. Cambridge, MA: Cambridge University Press, 811-841. 